\title{
Biologia floral e fenologia reprodutiva do camu-camu (Myrciaria dubia (H.B.K.) McVaugh, Myrtaceae) no Estado Pará, Brasil
}

\author{
MÁRCIA M. MAUÉS ${ }^{1,3}$ e GUY COUTURIER ${ }^{2}$
}

(recebido: 11 de janeiro de 2001; aceito: 4 de julho de 2002)

\begin{abstract}
Floral biology and reproductive phenology of the camu-camu (Myrciaria dubia (H.B.K.) McVaugh, Myrtaceae) in the State of Pará, Brazil). The camu-camu (Myrciaria dubia (H. B.K.) McVaugh, Myrtaceae) is a native fruit tree found on seasonaly flooded banks of Amazonian rivers and lakes, which is being domesticated for cultivation on non-flooded areas. Its high ascorbic acid content, approximately $2,800 \mathrm{mg} 100 \mathrm{~g}^{-1}$ of pulp has increased the demand for local market and exportation. The floral biology and reproductive phenology of camu-camu were investigated in 1997 and 1998. The studies were carried out in orchards at Embrapa Amazônia Oriental, located in Belém and in areas of natural occurrence in Santarém and Oriximiná, Pará State, northern Brazil. Direct observations on the visitors behavior were done, as well as capturing of specimens for identification. M. dubia showed inflorescences with white, polyandrous, hermaphroditic flowers. Anthesis occurred between 5:00 to 7:00 a.m. The pollen grains are dry, easily carried by wind or gravity, being the main flower resource. The osmophores are located at the calyx, corolla, anthers and stigma. The flowering phenology was "steady-state" type, and showed a peak in March. Fruitification was higher in July. Partial leaf fall was observed in all the studied plants, mainly in November. The main flower visitors were Nannotrigona punctata and Trigona pallens (Meliponinae), as well as small beetles (Chrysomelidae). The stingless bees were considered the legitimate pollinators.
\end{abstract}

RESUMO - (Biologia floral e fenologia reprodutiva do camu-camu (Myrciaria dubia (H.B.K.) McVaugh, Myrtaceae) no Estado do Pará, Brasil). O camu-camu (Myrciaria dubia (H.B.K.) McVaugh, Myrtaceae) é uma fruteira nativa que ocorre nas margens de rios e lagos inundáveis da Amazônia, e está sendo domesticada visando o cultivo em terra firme. O alto teor de ácido ascórbico nos frutos, cerca de $2.800 \mathrm{mg} .100 \mathrm{~g}^{-1}$ de polpa, fortalece a demanda para consumo no país e exportação. No período de 1997 a 1998, investigou-se a biologia floral e fenologia reprodutiva do camu-camu, em plantios da Embrapa Amazônia Oriental, em Belém, e em áreas de ocorrência natural, em Santarém e Oriximiná, no Estado do Pará, norte do Brasil. Observações diretas sobre o comportamento dos visitantes foram acompanhadas da coleta de espécimens para identificação e registro fotográfico. M. dubia apresenta inflorescências com flores brancas, hermafroditas e poliândricas. A antese ocorre entre as 5:00 e 7:00 h. O pólen é seco e facilmente transportado pelo vento ou gravidade, sendo o principal recurso e atrativo floral. Os osmóforos estão localizados no cálice, corola, anteras e estigma. Constatou-se que a fenofase de floração foi do tipo "steady-state", sendo mais expressiva em março e a frutificação teve um pico no mês de julho. Observou-se desfolha parcial em todas as plantas estudadas, principalmente em novembro. Os principais visitantes foram Nannotrigona punctata e Trigona pallens (Meliponinae) e pequenos besouros (Chrysomelidae). As abelhas sem ferrão foram consideradas os polinizadores legítimos.

Key words - Amazon region, bees, native fruit tree, melittophily, pollination

\section{Introdução}

A Amazônia apresenta um dos maiores índices de biodiversidade do mundo, no qual estão incluídas espécies vegetais com grande potencial econômico ainda não domesticadas. O camu-camu (Myrciaria dubia (H.B.K.) McVaugh, Myrtaceae) é uma fruteira nativa de porte arbustivo, encontrado nas margens inundáveis dos rios e lagos da Bacia Amazônica (Villachica 1996).

\footnotetext{
1. Embrapa Amazônia Oriental, Laboratório de Entomologia, Caixa Postal 48, 66017-970 Belém, Pará, Brasil.

2. Museum National d'Histoire Naturelle, Antenne IRD/MNHN, 45, rue Buffon, 75005, Paris, France.

3. Autor para correspondência: marcia@cpatu.embrapa.br
}

A espécie distribui-se por grande parte da Amazônia brasileira, nos Estados do Pará, Amapá, Amazonas, Rondônia, Roraima e Mato Grosso. É encontrada, ainda, na Amazônia peruana e na Amazônia venezuelana (McVaugh 1963). De acordo com Villachica (1996), a Amazônia peruana apresenta as populações mais expressivas de M. dubia, observando-se em algumas localidades, formações praticamente monoespecíficas.

No Brasil, nas áreas de ocorrência natural, a espécie é conhecida por diversos nomes vernáculos: araçá, araçarana, araçazinho, araçá-d'água, araçá-do-lago, caçari, murta, sarão e socoró, entretanto, a maioria das referências sobre $M$. dubia adotou a denominação que a espécie recebe no Peru, camu-camu (Villachica 1996). Os nomes usados pela população ribeirinha da 
Amazônia Brasileira têm sido pouco considerados na literatura.

O fruto de Myrciaria dubia é uma baga esférica de superfície lisa e brilhante, coloração vermelho-arroxeada, com dois a quatro centímetros de diâmetro e uma a quatro sementes, apreciado para a confecção de sorvetes, sucos e licores, com grande potencial econômico (Villachica 1996). A dispersão das sementes é endozoocórica, feita principalmente por peixes como o tambaqui (Colossoma macropomum Cuvier 1818, Caracidae), e pela própria correnteza dos cursos d'água (Yuyama \& Siqueira 1999).

Segundo Leslie (1998) e Andrade et al. (1995), o camu-camu apresenta o mais elevado teor de ácido ascórbico (2.880 mg. $100 \mathrm{~g}^{-1}$ de polpa) se comparado com outras frutas tropicais como a acerola $\left(1.790 \mathrm{mg} .100 \mathrm{~g}^{-1}\right.$ de polpa), o caju (220 mg. $100 \mathrm{~g}^{-1}$ de polpa) e a laranja (41 mg.100 g-1 de polpa). Zapata \& Dufour (1993) confirmaram a alta concentração de ácido ascórbico na polpa do camu-camu. Esta característica faz com que exista um mercado promissor para esta fruta no país e no exterior (Leslie 1998, Ferreira \& Gentil 1997).

Peters \& Vasquez $(1986 / 1987)$ estudaram a densidade e a estrutura de uma população natural de camu-camu na Bacia do Rio Ucayali, no Peru, e registraram as primeiras informações sobre a biologia floral, relatando que as flores são hermafroditas, apresentando uma elevada taxa de geitonogamia, sendo descritos como principais vetores de polinização, naquela região, o vento e as abelhas sem ferrão da subfamília Meliponinae.

Instituições de pesquisa brasileiras e peruanas vêm desenvolvendo pesquisas sobre a domesticação de M. dubia, através de programas de melhoramento genético para cultivo em terra firme (Clement et al. 1982, Couturier et al. 1999).

O conhecimento dos padrões fenológicos e da biologia floral, a determinação do papel dos vetores de fluxo de pólen, além do entendimento do sistema reprodutivo, são pontos fundamentais para a compreensão da biologia reprodutiva da espécie e base para o desenvolvimento de programas de melhoramento genético. O presente trabalho foi desenvolvido em duas condições: em plantio e em áreas de ocorrência natural. São apresentados e discutidos aspectos relacionados à biologia floral, polinização e fenologia reprodutiva.

\section{Material e métodos}

As investigações foram conduzidas em 1997 e 1998, no Banco Ativo de Germoplasma (BAG) de camu-camu
(Myrciaria dubia (H.B.K.) McVaugh) da Embrapa Amazônia Oriental, em Belém, Pará, instalado em uma área de terra firme $\left(1^{\circ} 28^{\prime} \mathrm{S}\right.$ e $\left.48^{\circ} 29^{\prime} \mathrm{W}\right)$. O BAG de camu-camu foi instalado em 1994 e possui 11 acessos, provenientes de populações encontradas nos municípios de São Paulo de Olivença e Atalaia do Norte, Estado do Amazonas. Existem cerca de 139 plantas, com três a cinco plantas de cada acesso. O espaçamento utilizado para plantio foi de $4 \mathrm{~m} \times 4 \mathrm{~m}$, com bordadura simples circundando a área experimental, que mede $4.160 \mathrm{~m}^{2}$.

As investigações em regiões de ocorrência natural da espécie foram realizadas nas margens de rios, lagos e praias, situados nos municípios de Oriximiná (Rio Trombetas) e Santarém (Rio Tapajós).

O tipo climático de Belém obedece ao padrão Afi, de acordo com a escala de Köppen, caracterizado por temperatura do ar média anual de $25,9^{\circ} \mathrm{C}$ (variando entre $21^{\circ} \mathrm{C}$ e $31,6^{\circ} \mathrm{C}$ ); umidade relativa do ar de $84 \%$ e precipitação pluviométrica de $2.900 \mathrm{~mm}$.ano ${ }^{-1}$. Nas regiões de Santarém e Oriximiná o clima é do tipo Ami, com temperatura média de $25{ }^{\circ} \mathrm{C}$, umidade relativa do ar de $86 \%$, precipitação pluviométrica de $2.100 \mathrm{~mm}$. ano ${ }^{-1}$.

Para os estudos de fenologia reprodutiva foram selecionadas, aleatoriamente, 54 plantas no BAG da Embrapa Amazônia Oriental, incluindo quatro a cinco plantas de cada acesso, que receberam um número de identificação. No período de agosto de 1997 a julho de 1998, foram feitas observações quinzenais sobre a ocorrência dos eventos de floração (botão floral e flor), frutificação (fruto verde e fruto maduro, disseminação) e mudança foliar (folha nova e folha madura, desfolha parcial e desfolha total), segundo metodologia de Fournier \& Charpantier (1975). Os dados fenológicos foram correlacionados a registros meteorológicos provenientes da Estação Meteorológica da Embrapa Amazônia Oriental.

Foram estudados aspectos da biologia floral (determinação da antese, morfologia floral, presença de osmóforos, receptividade do estigma e viabilidade do pólen), principalmente nas plantas do BAG da Embrapa Amazônia Oriental.

A receptividade do estigma foi testada através do Perex Test Merk (Dafni 1992), Peroxtesmo KO (Dafni \& Maués 1998), peróxido de hidrogênio $\left(\mathrm{H}_{2} \mathrm{O}_{2}\right)$ a $3 \%$ (Kearns \& Inouye 1993) e solução Baker (Dafni 1992). O Perex Test indica a presença de peróxido de hidrogênio $\left(\mathrm{H}_{2} \mathrm{O}_{2}\right)$ no estigma, sendo medido através de uma escala de cores que varia do amarelo claro ao vermelho, com escores para cada nuance. A solução de Peroxtesmo KO indica a presença de uma enzima, a peroxidase, sendo que o estigma receptivo assume uma coloração azul ou roxa na presença desta enzima. O peróxido de hidrogênio $\left(\mathrm{H}_{2} \mathrm{O}_{2}\right)$ indica a receptividade através da formação de bolhas de ar, é um método simples e barato, porém a presença de qualquer corte no tecido, pode levar a um falso resultado. O teste de Baker indica, também, a presença de atividade enzimática, através da presença de 
álcool desidrogenase, a região de maior receptividade no estigma torna-se azul-escura ou arroxeada.

A viabilidade do pólen foi testada utilizando-se solução Baker (Dafni 1992). Este método é o mesmo utilizado para a determinação da receptividade do estigma. Os grãos de pólen viáveis tornam-se azuis, em contato com a solução, e os que não estão viáveis permanecem com a coloração inalterada.

As glândulas secretoras de aroma (osmóforos) foram localizadas utilizando-se solução de vermelho-neutro (1:10.000; Kearns \& Inouye 1993). Flores frescas foram submersas na solução durante 60 minutos. Após esta etapa, as flores foram lavadas em água destilada e dissecadas sob estereoscópio para a análise das partes florais. As regiões coradas de vermelho intenso indicaram a presença dos osmóforos.

A morfologia floral foi analisada em flores fixadas em FAA, com ênfase na estrutura dos órgãos sexuais (Radford et al. 1974). A morfologia polínica foi investigada através de microscopia óptica, principalmente quanto à ornamentação.

Observações diretas sobre o comportamento dos visitantes nas flores foram acompanhadas da coleta de espécimes para identificação e registro fotográfico. Durante as visitas, foi observado o local de contato do visitante com as partes florais, bem como a movimentação deste entre as flores. Esses estudos foram feitos no período das 6:00 h às 9:00 h, em função do horário de atividade dos visitantes, durante 15 dias, nos meses de maior intensidade de florescimento (agosto a novembro de 1997 e maio de 1998) totalizando, aproximadamente, 45 horas de observação. Esta etapa foi realizada no BAG e nas áreas de ocorrência natural. Os insetos coletados foram identificados por especialistas e/ou por comparação com exemplares do acervo da Coleção Entomológica da Embrapa Amazônia Oriental. Espécimes "voucher" foram depositados na referida coleção.

\section{Resultados e Discussão}

Nas áreas estudadas, Myrciaria dubia é um arbusto que atinge até $1,5 \mathrm{~m}$ de altura e apresenta inflorescências axilares, com flores polistêmones (média: $211, \mathrm{n}=35$ ) do tipo "pincel" (figura 1); diâmetro variando de 1 a $1,4 \mathrm{~cm}$, sub-sésseis, brancas, hermafroditas; cálice gamossépalo; corola dialipétala, cruciforme, com pétalas côncavas e pubescentes; anteras basifixas introrsas e rimosas; ovário ínfero e estigma filiforme, papiloso.

A antese se inicia em torno das 5:00 h da manhã e, até as 7:00 h, podem ser encontradas flores em processo de abertura. O estigma está exposto muito antes da completa abertura das flores, indicando a ocorrência de protoginia. A exposição do pólen ocorre cerca de 30 minutos após a antese. O pólen é relativamente pequeno,

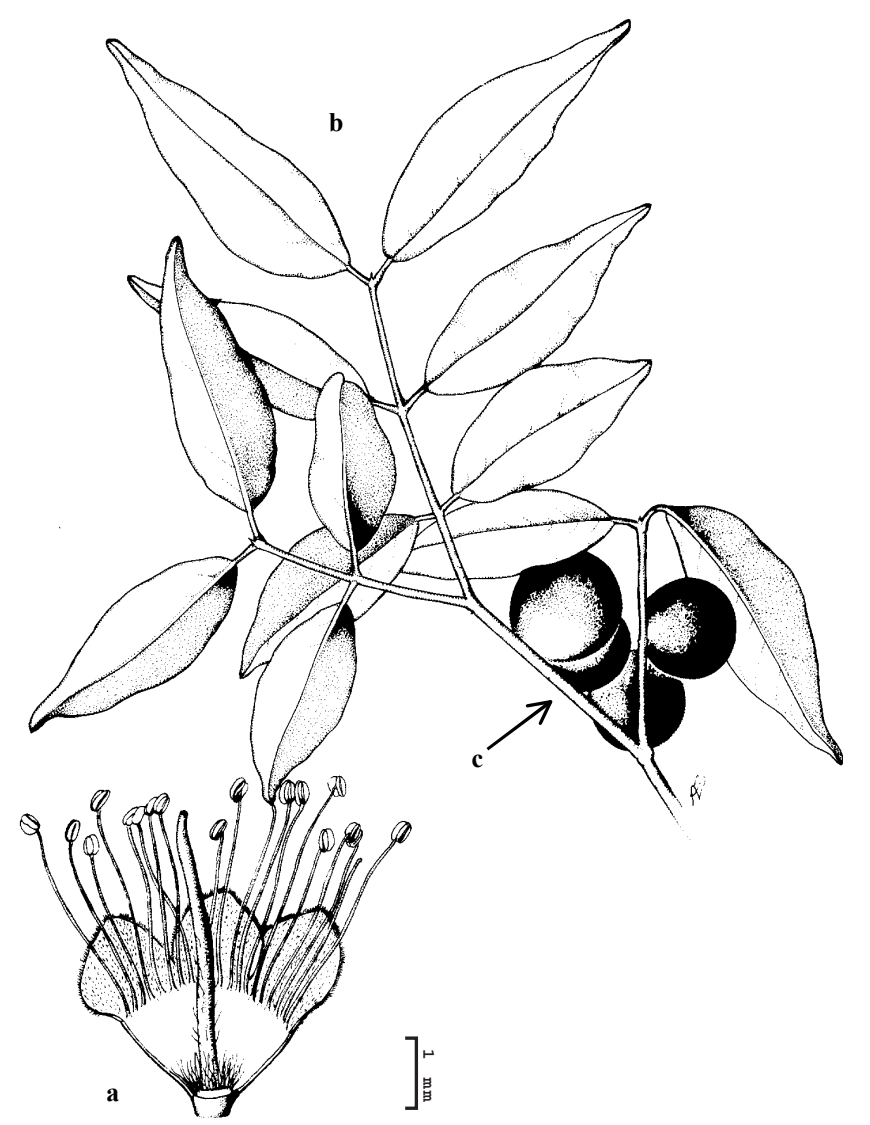

Figura 1. Camu-camu (Myrciaria dubia). Corte longitudinal de uma flor (a), ramo frutífero (b) e frutos maduros (c).

se comparado ao de outras mirtáceas (Barth \& Barbosa 1972), com superfície granulosa e seca, o que o torna facilmente transportável pelo vento.

As flores são aromáticas, exalando odor agradável e adocicado. Osmóforos estão presentes principalmente no cálice, corola, anteras e estigma. Cerca de quatro horas após a antese, as flores entram em senescência, facilmente notada pela flacidez e mudança de coloração dos estames, que passam da coloração branca ao bege, aliada à abscisão e à queda dos mesmos. As flores duram apenas um dia, corroborando a regra geral para Myrtoideae (Lughadha \& Proença 1996). Os estames numerosos devem ser importantes para a atração visual dos visitantes, assim como o aroma exalado pelas flores. Verificou-se que há produção de néctar, pois as abelhas visitantes foram observadas coletando este recurso, entretanto não foram feitas medições de volume e concentração de açúcares.

O estigma é filiforme e úmido. A receptividade do estigma manifestou-se imediatamente após a antese e estendeu-se até cerca de cinco horas depois. A área de maior receptividade no estigma concentra-se na região 
apical central. O pólen constituiu a maior recompensa aos visitantes, e apresentou elevada viabilidade (89\%) no período compreendido entre as 7:00 h e as 8:00 h, observando-se uma queda no porcentual de viabilidade após as 8:30 h (56\%). Estes resultados diferem do que foi relatado por Peters \& Vasquez (1986/1987), ao afirmarem que o estigma permanecia receptivo por 4-5 horas, porém este período não coincidia com a viabilidade do pólen. Nas plantas que fizeram parte deste estudo, verificou-se que havia sincronismo entre a viabilidade do pólen e a receptividade do estigma, por um período de 60 a 90 minutos, ocorrendo superposição das funções reprodutivas masculinas e femininas, invalidando outra afirmação de que a protoginia acentuada, conduzindo à dicogamia, impediria a autofecundação. Os autores afirmam, ainda, que flores isoladas para testes de autofecundação não formaram frutos devido à dicogamia, porém acreditamos que a exclusão dos agentes polinizadores foi o principal motivo da inexistência de frutos neste experimento. A autofecundação poderia ser impedida por fatores genéticos, não testados nesse estudo.

Considerando-se as plantas estudadas no BAG de Myrciaria dubia da Embrapa Amazônia Oriental, verificou-se que a fenofase de floração ocorreu durante o ano todo, mesmo que em baixa proporção, sendo mais expressiva nos meses de setembro de 1997, março e junho de 1998 (figura 2). De acordo com o sistema de Gentry (1974), o padrão que mais se aproximou do tipo de floração observado para esta espécie foi o "steady state". Estes resultados confirmam os registros feitos por Falcão (1993), quanto à floração de um plantio de camu-camu em terra firme, na região de Manaus, AM. Entretanto, Lughadha \& Proença (1996) não concordam com a autora, pois comentam que este padrão pode não caracterizar exatamente o tipo descrito por Gentry para "steady state", uma vez que ocorre um aumento na produção de flores em determinados períodos do ano.

Vale ressaltar que em outubro de 1997 foi registrada a presença de botões florais em $24 \%$ das plantas estudadas, mas houve perda de grande parte desses botões, resultando na ocorrência de floração em apenas $2 \%$ dos indivíduos. Atribuiu-se este fato à baixa pluviosidade registrada no período, provocada pelo fenômeno "El Niño", registrado em 1997 e 1998, que é caracterizado pelo aquecimento anômalo das águas superficiais do Pacífico Equatorial Oriental e responsável pela redução de chuvas na Amazônia (CPETEC-INPE 1999). Seria recomendável avaliar o uso de um sistema de irrigação nos meses de menor pluviosidade, a fim de reduzir o abortamento de botões, acentuando esses cuidados em períodos de ocorrência do evento "El Niño". Villachica (1996) relata a maior intensidade de floração nos meses de setembro a outubro em áreas de ocorrência natural da espécie no Peru.

A frutificação teve maior intensidade nos meses de maio a julho de 1998, quando $11 \%$ das plantas apresentaram frutos verdes e, destas, apenas 3\% mantiveram os frutos até o completo amadurecimento (figura 3), nos meses de julho a agosto de 1998. É importante observar que no plantio em terra firme a frutificação foi mais expressiva nos meses menos chuvosos, enquanto que em condições naturais, em

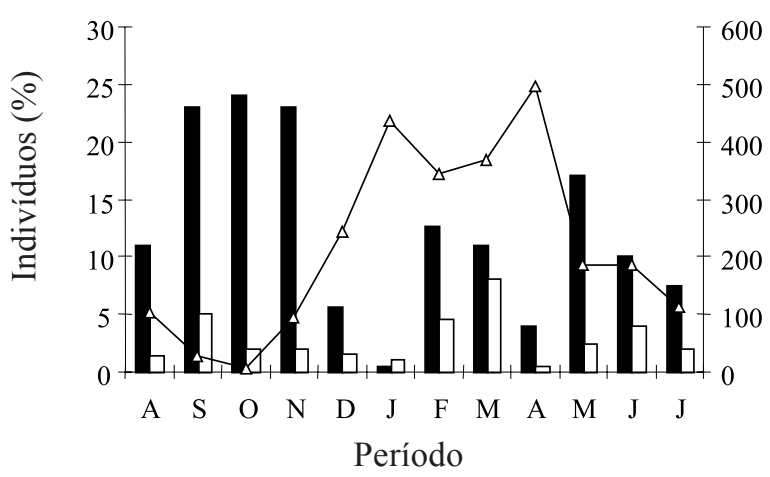

Figura 2. Fenofases reprodutivas de camu-camu (Myrciaria dubia) e precipitação pluviométrica mensal em terra firme na Embrapa Amazônia Oriental, no período de agosto de 1997 a julho de 1998 ( $\mathbf{\square}=$ botão floral; $\square=$ flor; $\Delta=$ precipitação).

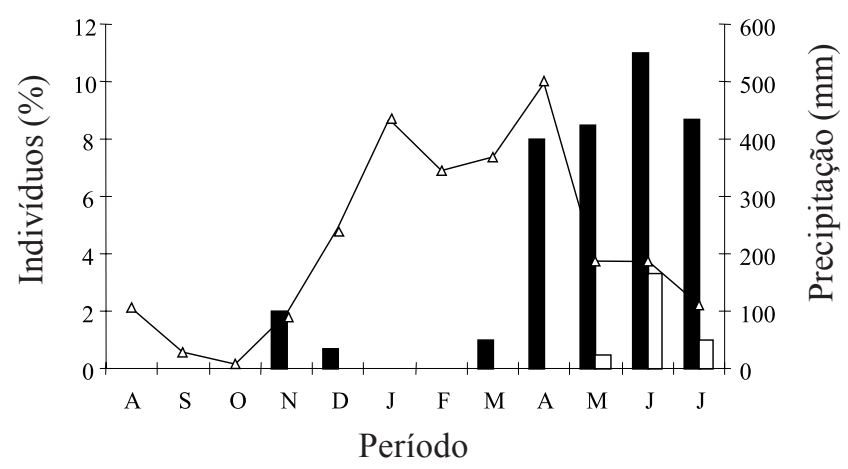

Figura 3. Fenofases reprodutivas de camu-camu (Myrciaria dubia) e precipitação pluviométrica mensal em terra firme na Embrapa Amazônia Oriental, no período de agosto de 1997 a julho de 1998 ( $\square=$ frutos verdes; $\square=$ frutos maduros; $\Delta=$ precipitação). 
áreas sazonalmente alagadas no Peru, a época de frutificação ocorre nos meses de dezembro a janeiro, após o início da descida das águas nos rios e em plantações em terra firme ocorreu em dois picos distintos, nos meses de setembro a outubro e março a abril (Villachica 1996). Ressalte-se, ainda, que a produção de frutos, no geral, foi considerada baixa, o que pode ser atribuído à idade do plantio e/ou à mudança do tipo de terreno em relação ao meio natural de ocorrência da espécie. Peters \& Vasquez (1986/1987) mencionam que apesar do uso de fertilizantes, a produtividade de Myrciaria dubia em plantios de terrafirme é muito baixa se comparada ao que se verifica em áreas naturais, fato que os autores atribuem à deficiência nutricional ou à falta de polinizadores.

Observou-se a perda parcial das folhas, com maior ocorrência entre os meses de outubro e dezembro de
1997, em até $100 \%$ das plantas estudadas. Não foi observada a perda total das folhas, indicando que esta planta é perenifólia.

Assim, os estudos fenológicos mostraram que a floração apresentou três picos distintos, dois no primeiro semestre, correspondendo ao período chuvoso na área de estudo, e um pico no segundo semestre, período de menor pluviosidade. As fenofases de floração e frutificação apresentaram assincronismo entre as plantas estudadas. Verificou-se, ainda, uma elevada taxa de abortamento de frutos imaturos nos meses de menor precipitação pluviométrica, o que pode indicar a necessidade de irrigação no plantio.

Diversos insetos foram observados visitando as flores de Myrciaria dubia. Uma lista com as principais espécies encontradas nas flores consta da tabela 1. Os visitantes mais importantes foram as abelhas sem ferrão

Tabela 1. Insetos visitantes das flores do camu-camu (Myrciaria dubia) em Belém, Santarém e Oriximiná (Pe = polinizadores efetivos; Po = polinizadores ocasionais).

\begin{tabular}{|c|c|c|}
\hline Espécie & Comportamento & Local \\
\hline \multicolumn{3}{|l|}{ HYMENOPTERA } \\
\hline \multicolumn{3}{|l|}{ Apidae } \\
\hline Apis mellifera L., 1758 & $\mathrm{Pe}$ & Belém \\
\hline Melipona compressipes fasciculata Smith, 1854 & $\mathrm{Pe}$ & Santarém \\
\hline Nannotrigona punctata (Smith, 1854) & $\mathrm{Pe}$ & Belém \\
\hline Partamona sp. & $\mathrm{Pe}$ & Belém \\
\hline Partamona aff. cupira Smith, 1863 & $\mathrm{Pe}$ & Belém \\
\hline Trigona branneri Cockerell, 1912 & $\mathrm{Pe}$ & Belém \\
\hline Trigona pallens Fabricius, 1798 & $\mathrm{Pe}$ & Belém \\
\hline Trigona recursa Smith, 1863 & $\mathrm{Pe}$ & Belém \\
\hline Exomalopsis cf. aureopilosa Spinola, 1854 & $\mathrm{Pe}$ & Belém \\
\hline Augochlora sp. & $\mathrm{Pe}$ & Belém \\
\hline \multicolumn{3}{|l|}{ Vespidae } \\
\hline Uma espécie não identificada & Po & Santarém \\
\hline \multicolumn{3}{|l|}{ DIPTERA } \\
\hline \multicolumn{3}{|l|}{ Syrphidae } \\
\hline Ornidia obesa Fabricius, 1775 & Po & Belém \\
\hline Duas espécies não identificadas & Po & Belém \\
\hline \multicolumn{3}{|l|}{ Stratiomyidae } \\
\hline Três espécies não identificadas & Po & Belém \\
\hline \multicolumn{3}{|l|}{ Cixiidae } \\
\hline Uma espécie não identificada & Po & Belém \\
\hline \multicolumn{3}{|l|}{ Calliphoridae } \\
\hline Uma espécie não identificada & Po & Santarém \\
\hline \multicolumn{3}{|l|}{ Otitidae } \\
\hline Euxesta sp. & Po & Belém \\
\hline \multicolumn{3}{|l|}{ COLEOPTERA } \\
\hline \multicolumn{3}{|l|}{ Chrysomelidae } \\
\hline Costalimaita ferruginea vulgata Lefevre, 1885 & Po & Belém \\
\hline Sete espécies não identificadas & Po & Belém \\
\hline Cinco espécies não identificadas & Po & Santarém \\
\hline
\end{tabular}


(Apidae: Meliponinae), seguidas de coleópteros das famílias Chrysomelidae, Coccinelidae, Scolytidae, Cerambycidae e Mellanotidae, outros himenópteros das famílias Anthophoridae e Vespidae e dípteros das famílias Syrphidae, Stratiomyidae, Calliphoridae.

Dentre os visitantes, as abelhas (Apis mellifera, Melipona compressipes fasciculata, Nannotrigona punctata, Partamona sp., Partamona aff. cupira, Trigona branneri, T. pallens, T. recursa, Exomalopsis cf. aureopilosa e Augochlora sp.) apresentaram comportamento compatível com a função de polinizadores legítimos. N. punctata, T. branneri e T. pallens (Apidae, Meliponinae) foram as espécies mais freqüentes nas coletas.

As abelhas chegavam às flores para coletar o pólen logo após a antese, estendendo as visitas até cerca das 9:00 h, movimentando-se entre as flores de uma mesma planta e entre plantas distintas, coletando néctar e pólen, este último, transportado aderido à porção ventral do tórax e abdome. Ao chegarem às flores através de uma abordagem frontal, estes insetos abraçavam um grupo de estames com as pernas anteriores e médias e faziam contato direto entre a região ventral do tórax e abdome com o estigma, muitas vezes promovendo a queda de estames ao movimentarem as pernas para coletar os recursos florais (figura 4). O pólen era transportado de uma flor para outra ao longo da região ventral do corpo das abelhas. Peters \& Vasquez (1986/1987) relatam apenas as abelhas Melipona fuscopilara e Trigona portica polinizando Myrciaria dubia no Peru. Lughadha \& Proença (1996) e Proença \& Gibbs (1994) mencionam que as abelhas são os principais polinizadores das mirtáceas na região central do Brasil.

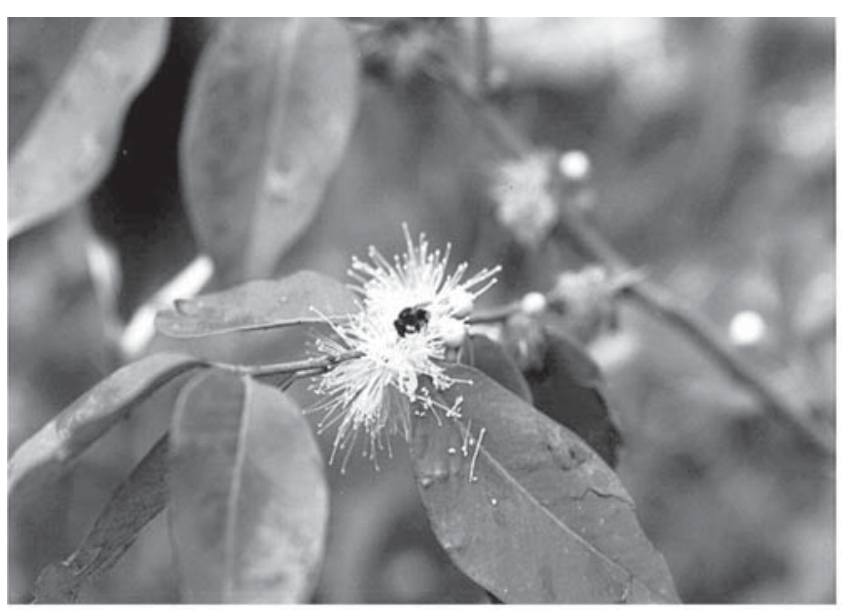

Figura 4. Trigona branneri coletando pólen em uma flor recém-aberta de camu-camu (Myrciaria dubia).
As moscas (Ornidia obesa e outros sirfídeos não identificados) fizeram visitas esporádicas e curtas, coletando pólen com o aparelho bucal, e transportando-o aderido à região frontal da cabeça, tórax e abdome. A freqüência de visitas foi bem menor que a verificada para as abelhas, indicando que esses agentes têm um papel secundário na polinização de Myrciaria dubia. Os dípteros encontrados nas flores pertencem a famílias reconhecidas pela abrangente revisão de Larson et al. (2001) como antófilos, podendo ser apenas visitantes florais (Stratyiomidae, Cixiidae, Calliphoridae, Otitidae) ou polinizadores ocasionais (Syrphidae).

Os crisomelídeos foram bastante freqüentes e diversificados, tanto na terra firme quanto nas áreas de ocorrência natural. Durante as visitas esses insetos pousavam diretamente sobre as anteras e coletavam pólen, eventualmente mantendo contato com o estigma. A maioria dos crisomelídeos observados nas flores apresentavam um tamanho muito reduzido, sendo este o principal motivo da falta de contato com o estigma durante as visitas. Os demais coleópteros também pousavam diretamente sobre as anteras, raras vezes contactando com o estigma, caminhando entre os estames coletando pólen, e promovendo, ocasionalmente, a transferência de pólen ao estigma. Costalimaita ferruginea vulgata foi encontrado freqüentemente nas flores, mas é conhecido por ser uma espécie polífaga com comportamento prejudicial ao camu-camu e a numerosas plantas cultivadas, pois se alimenta de brotos, folhas e botões florais, muitas vezes causando danos severos (Couturier et al. 1999). Assim, os coleópteros foram considerados polinizadores ocasionais ou ilegítimos.

De um modo geral as abelhas foram consideradas os polinizadores legítimos em função de seu comportamento durante as visitas, a freqüência de visitas observada em comparação com os demais insetos, e a compatibilidade de tamanho entre estas e as flores, o que proporcionava um contato mais eficiente com os órgãos reprodutivos.

Duas horas após a deiscência das anteras não se encontrava pólen nas flores, mesmo na ausência de visita de insetos. Peters \& Vasquez (1986/1987) relataram resultados semelhantes na amazônia peruana. Estes autores encontraram duas espécies de Melipona polinizando o camu-camu, mas ressaltaram a importância da anemofilia no processo reprodutivo da espécie. Sugere-se que sejam aplicados testes específicos para comprovar essa hipótese.

As observações de campo mostraram que, ao 
pousarem nas flores, algumas abelhas promoviam a queda de estames e a liberação de pólen que caia sobre as flores que estavam em um plano inferior nos ramos. Não se comprovou a ocorrência de fertilização por meio desse mecanismo, mas considerando-se que o pólen de camu-camu é seco e se desprende facilmente das anteras, infere-se que a anemofilia pode contribuir para a formação de frutos. Os estudos feitos por Peters \& Vasquez (1986/1987) mostraram claramente a ocorrência de auto-fecundação, ao serem feitas fertilizações entre flores de uma mesma planta. Assim, os insetos que visitam as flores de Myrciaria dubia, facilitariam a remoção e deslocamento do pólen, resultando em uma síndrome denominada ambófila (sensu Bullock 1994).

De acordo com Endress (1994), plantas que possuem flores do tipo "pincel" são exploradas e polinizadas por uma grande variedade de animais. Em M. dubia, observou-se uma entomofauna diversificada visitando as flores em busca dos recursos florais, dentre os quais destacaram-se as abelhas, moscas e besouros.

Pelos estudos realizados, foi possível concluir que o camu-camu é um cultivo promissor em condições de terra firme, porém devem ser intensificados estudos sobre a irrigação, em vista da excessiva queda de frutos observada, principalmente, durante os meses de menor pluviosidade.

Agradecimentos - Ao Dr. David Roubik, pela identificação das abelhas. Aos funcionários do Laboratório de Entomologia da Embrapa Amazônia Oriental, Francisco Gomes da Silva Frota, Domingos de Jesus Araújo e Almir Lopes de Araújo, pelo apoio nos trabalhos de campo. Ao Sr. Elielson Rocha, pela ilustração botânica. Este trabalho recebeu recursos do Fundo Estadual de Ciência e Tecnologia (Funtec), através da Secretaria Executiva de Ciência, Tecnologia e Meio Ambiente (Sectam) do Estado do Pará.

\section{Referências bibliográficas}

ANDRADE, J.S., ARAGÃO, C.G., GALEAZZI, M.A.M. \& FERREIRA, S.A.N. 1995. Changes in the concentration of total vitamin $\mathrm{C}$ during maturation and ripening of camu-camu (Myrciaria dubia) fruits cultivated in the upland of Brazilian Central Amazon. Acta Horticulturae 370:177-180.

BARTH, O.M. \& BARBOSA, A.F. 1972. Catálogo sistemático dos pólens das plantas arbóreas do Brasil meridional XV. Myrtaceae. Memórias do Instituto Oswaldo Cruz 70:467-495.

BULLOCK, S.H. 1994. Wind pollination of Neotropical dioecious trees. Biotropica 26:172-179.
CLEMENT, C.R., MÜLLER, C.H. \& FLORES, W.B. 1982. Recursos genéticos de espécies frutíferas nativas da Amazônia. Acta Amazonica 12:677-695.

COUTURIER, G., SILVA, J.F., SILVA, A.B. \& MOTTA, M.M. 1999. Insetos que atacam o camu-camuzeiro (Myrciaria dubia (H.B.K.) McVaugh, Myrtaceae) em cultivos paraenses. Comunicado Técnico 3. Embrapa Amazônia Oriental, Belém.

CPTEC-INPE. 1999. http://www1.cptec.inpe.br/products/ elninho/elninholp.html.

DAFNI, A. 1992. Pollination ecology: a practical approach. IRL, Oxford.

DAFNI, A. \& MAUÉS, M.M. 1998. A rapid and simple procedure to determine stigma receptivity. Sexual Plant Reproduction 11:117-180.

ENDRESS, P.K. 1994. Diversity and evolutionary biology of tropical flowers. Cambridge University Press, Cambridge.

FALCÃO, M.A. 1993. Aspectos fenológicos, ecológicos e de produtividade de algumas fruteiras cultivadas na Amazônia. $2^{\mathrm{a}}$ ed. Ufam, Manaus v.2.

FERREIRA S.A.N. \& GENTIL, D.F.O. 1997. Propagação assexuada do camu-camu (Myrciaria dubia) Acta Amazonica 27:163-168.

FOURNIER, L.A.O. \& CHARPANTIER, C. 1975. El tamaño de la muestra y la frecuencia de las observaciones en el estudio da las características de los árboles tropicales. Turrialba 25:45-48.

GENTRY, A.H. 1974. Flowering phenology and diversity in tropical Bignoniaceae. Biotropica 6:64-68.

KEARNS, C.A. \& INOUYE, D.W. 1993. Techniques for pollination biologists. University Press of Colorado, Niwot.

LARSON, B.M.H., KEVAN, P.G. \& INOUYE, D.W. 2001. Flies and flowers: taxonomic diversity of anthophiles and pollinators. The Canadian Entomologist 133:439-465.

LESLIE, T. 1998. Herbal secrets of the rainforest. Prima Publishing, Austin.

LUGHADHA, E.N. \& PROENÇA, C. 1996. A survey of the reproductive biology of the Myrtoideae (Myrtaceae). Annals of the Missouri Botanical Garden 83:480-503.

McVAUGH, R. 1963. Tropical American Myrtaceae. II. Field Museum of Natural History, Botanical Series 29:315-532.

PROENÇA, C.E.B. \& GIBBS, P.E. 1994. Reproductive biology of eight sympatric Myrtaceae from Central Brazil. New Phytologist 126:343-354.

PETERS, C.M. \& VASQUEZ, A. 1986/1987. Estudios ecologicos de camu-camu (Myrciaria dubia) I. producción de frutos en poblaciones naturales. Acta Amazonica. 16/17:161-174. 
RADFORD, A.E., DICKSON, W.C., MASEY, J.R. \& BELL, C.R. 1974. Vascular plant systematics. Harper \& Row, New York.

VILLACHICA, H.L. 1996. El cultivo del camu-camu (Myrciaria dubia (H.B.K.) McVaugh) en la Amazonia peruana. Mirigraf, Lima.
YUYAMA, K. \& SIQUEIRA, J.A.S. 1999. Efeitos do tamanho da semente e do recipiente no crescimento de mudas de camu-camu (Myrciaria dubia). Acta Amazonica 29:647-650.

ZAPATA, S.M. \& DUFOUR, J.P. 1993. Camu-camu Myrciaria dubia (H.B.K.) McVaugh: chemical composition of fruit. Journal of Science and Agriculture 61:349-351. 